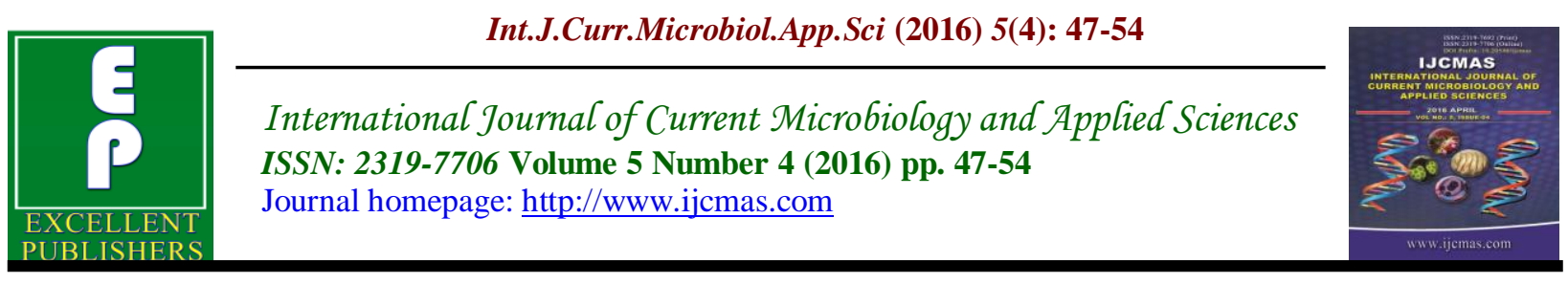

Original Research Article

http://dx.doi.org/10.20546/ijcmas.2016.504.008

\title{
Bacterial Uropathogens and Empirical Treatment in Urinary Tract Infection in a Tertiary Care Institute
}

\author{
Surinder Kumar*, Diksha Budhani and Pallavi Sayal \\ Department of Microbiology, BPS GMC (W)Khanpur Kalan, Sonepat, India \\ *Corresponding author
}

\begin{abstract}
A B S T R A C T
Keywords

Urinary Tract Infection, Gram

Negative Bacilli,

Empirical

Treatment, Antibiotics.

Article Info

Accepted:

08 March 2016

Available Online:

10 April 2016

The aim of study was to determine the bacterial uropathogens and empirical treatment in urinary tract infection in a tertiary institute. The present study was conducted in Department of Microbiology of a tertiary care hospital in North India from July to September 2015.A total of 2200 samples from the outpatient department (OPD) and inpatient department (IPD) were recruited for this study. Urine culture was done by semi-quantitative method. Antibiotic sensitivity was done as per Clinical and Laboratory Standards Institute (CLSI) guidelines. Out of 2200 samples 390 were culture positive (17.7\%). The prevalence of UTI was more in females (66.66\%). Escherichia coli was the predominant causative bacteria (48.41\%). Gram negative bacilli isolated showed maximum sensitivity to imipenem, amikacin and nitrofurantoin and Gram positive cocci to vancomycin and linezolid. Imipenem, Amikacin and Nitrofurantoin can be used as empirical treatment in patients with symptoms of UTI.
\end{abstract}

\section{Introduction}

Urinary tract infection (UTI) is a significant and a serious health affecting problem encountered both in the community and hospital settings each year worldwide (Bano et al., 2012). It is one of the most important cause of morbidity in the world affecting all age groups and involving both genders and usually requires medical treatment (Omoregie et al., 2008).Urinary tract infection is defined as bacteriuria along with urinary symptoms. It may involve only the lower urinary tract or may involve both the upper and lower tract.
The symptoms of UTI includes dysuria, frequency, urgency, and suprapubic tenderness (Zelikovic et al., 1992). Most of the UTI are caused by Gram negative bacteria like Escherichia coli, Proteus spp., Klebsiella spp., Pseudomonas aeruginosa, Acinetobacter, Serratia and Morganella morgani. Enterococcus, Staphylococcus especially coagulase negative staphylococci and Streptococcus agalactiaeare the important Gram positive bacteria responsible for UTI (Mohamed Shaaban et al., 2012). Among both outpatients and inpatients, Escherichia coliis the most 
common urinary tract pathogen, accounting for $75 \%$ to $90 \%$ of both community acquired and hospital acquired UTI. UTI is much more common in females than males due to anatomical and physiological reasons. The anatomical position of urogenital tract in females is responsible for bacterial infections caused by both internal and external flora (Shanthi, 2012).

The extensive use of antimicrobial agents have invariably led to the development of antibiotic resistance, which, in recent years, has become a significant problem worldwide (Kumar MS et al., 2006). In almost all cases of UTI, empirical antimicrobial treatment initiates before the laboratory results of urine culture are not available. This frequent use of antibiotics often leads to increase in antibiotic resistance in uropathogens. The magnitude of problem of drug resistance in patients with UTI is increasing and varies according to geographical and regional location (Mohamed Shaaban et al., 2012).

This study determines the prevalent uropathogens and their antibiogram according to age and sex at a medicalcollege hospital among outpatient department (OPD) and inpatient department (IPD). In the present scenario, where the antibiotic resistance pattern ischanging, our study aims at outlining the recommendations for empirical treatment of UTI. Moreover, the data would also help authorities to formulate antibiotic prescription policies.

\section{Materials and Methods}

Sample collection: The present retrospective study was conducted in the Department of Microbiology at a tertiary level teaching health care facility from July 2015 to Sep 2015. A total of 2200 urine samples were received from both indoor and outdoor patients irrespective of age and gender. Freshly voided, clean-catch midstream urine was collected from each patient into sterile screw-cappeduniversal container. The specimen was labelled and transported to the microbiology laboratory for processing within 2 hours of collection.

\section{Isolation and Identification}

Routine microscopic examination of urine samples was done to look for pus cells, red blood cells and epithelial cells. Semi quantitative urine culture was done using a calibrated loop. A loopful (0.001 ml) of well mixed uncentrifuged urine was inoculated onto the surface of blood agar and MacConkey agar. All plates were then incubated at $37^{\circ} \mathrm{C}$ aerobically for $24 \mathrm{hrs}$. The plates were then examined macroscopically for bacterial growth. A significant growth is considered if the number of colony is $>10^{5}$ colony forming unit $(\mathrm{cfu}) / \mathrm{ml}$. The colonies were further processed for identification by Gram staining, oxidase test, catalase test and other standard biochemical tests.

\section{Antimicrobial Susceptibility Testing}

The isolates were subjected to antibiotic susceptibility testing by Kirby-Bauer disc diffusion method using CLSI criteria on Mueller-Hinton agar (MHA) (CLSI document, 2006). Antibiotic discs used in the study were procured from $\mathrm{Hi}$-media ${ }^{\circledR}$ Laboratories, Mumbai, India and from BD diagnostics $®$ USA. American Type Culture Collection (ATCC) strain viz. E. coli. ATCC 25922 was employed as a control strain (Koneman's color Atlas and Textbook of Diagnostic Microbiology, 6th edn). Discs of the following antimicrobial agents, with their disc concentration, in brackets, were used: Amikacin $(30 \mu \mathrm{g})$, Gentamycin $(10 \mu \mathrm{g})$, Ciprofloxacin $(5 \mu \mathrm{g}), \quad$ Ceftriaxone $\quad(30 \mu \mathrm{g})$, Ampicillin/sulbactam(10/10mcg), Imipenem 
$(10 \mu \mathrm{g})$, Cefoxitin (30g), Cefazolin (30mcg), Nitrofurantoin $(300 \mathrm{mcg})$, Cefepime $(30 \mu \mathrm{g})$, Ofloxacin $(5 \mathrm{mcg})$, Linezolid $(15 \mu \mathrm{g})$ and Vancomycin $(30 \mu \mathrm{g})$ and Azithromycin (15mcg). The results were read after overnight incubation and compared with standard chart

\section{Results and Discussion}

Out of 2200 samples, 390 urine samples yielded significant growth(17.7\%).Out of these 390 isolates, 252(64.61\%) isolates were from OPD and 138(35.38\%) from IPD.(Table I) Among these 390 isolates, $345(88.46 \%)$ were gram negative bacilli and $45(11.54 \%)$ were gram positive cocci. Escherichia coli was the most commonly isolated urinary pathogen $(46.41 \%)$ followed by Enterobacter spp (15.64\%), Klebsiella spp (12.82\%) and Staphylococcus aureus $(5.12 \%)$. (Table I) Male and female culture positivity was $47.61 \%(120 / 252)$ and $52.38 \%(132 / 252)$ in OPD and $7.24 \%(10 / 138)$ and $92.75 \%(128 / 138)$ respectively in IPD samples.(Table II) Forty three per cent of all E.coli isolates were found to be resistant to ciprofloxacin. Resistance to the aminoglycosides amikacin and gentamicin was low, 6.72 and 13.55 percent respectively. The percentage of isolates of $E$. coli resistant to ampicillin/sulbactam was found to be as much as 57.52 per cent. The rates of resistance among Gram-negative uropathogens to third generation cephalosporins like ceftriaxone were high. Ceftriaxone resistance were seen in 56.48 and 46.6 per cent of all isolates of $E$. coli and $K$. pneumoniae. Resistance to imipenem and nitrofurantoin was comparatively less among isolates of E.coli (Table III and IV). Amongst the Gram-positive isolates, Staphylococcus aureus was the most commonly isolated organism with 6.6 per cent resistance to vancomycin. Resistance to ofloxacin, nitrofurantoin and gentamicin was $33.33 \%, 20 \%$ and $13.3 \%$ respectively (Table V and VI).

Effective management of patients suffering from bacterial UTIs depends majorly on the type of organisms and selection of an effective antibiotic agent to the organism. Diagnosis of UTIs and its treatment requires a good cooperation between the clinician and the microbiologist. In our study prevalence rate of infection of urinary pathogen was $17.72 \%$ which is similar to study by Kattel et al., 2008 in which $26 \%$ of urine specimens showed significant bacterial growth. The prevalence of UTI is more in females (66.66\%) when comparing males $(33.33 \%)$. This correlates with other study reported by Adedeji et al., in 2009.Women are more prone to UTIs than men because of short urethra and close proximity to the anus. Among patients with UTI, females were most commonly in the age group between 21-40 years and males were between 41-60 years.

The results were similar to a study by Nerukar in 2012, who reported that $52.16 \%$ females were in the age group 21-40 years. He concluded that most uncomplicated urinary tract infections occurs in women who are sexually active, as compared to older women, those who are pregnant, and in men. In older men, the incidence of UTI may increase due to prostatic obstruction or subsequent instrumentation. This was in consistent with the study by Banerjee et al. 2009. E.coli was the predominant bacteria $(48.41 \%)$ found in our study. This result is consistent with reports from other studies Abubakar, 2009, Daza et al., 2001. In our study gram negative bacilli isolated from UTI were sensitive to imipenem, amikacin, nitrofurantoin. 
Table.1 Distribution of Organisms Causing UTI

\begin{tabular}{|c|c|c|c|c|c|}
\hline \multirow[t]{2}{*}{ Organism } & \multicolumn{2}{|c|}{$\begin{array}{c}\text { Isolates causing UTI in OPD } \\
\text { patients }\end{array}$} & \multicolumn{3}{|c|}{ Isolates causing UTI in IPD patients } \\
\hline & $\begin{array}{c}\text { No. of } \\
\text { isolates }\end{array}$ & Percentage $(\%)$ & No. of isolates & Percentage (\%) & P-Value \\
\hline Escherichia coli & 122 & 48.41 & 59 & 42.75 & 0.284 \\
\hline Enterobacter spp. & 35 & 13.88 & 26 & 18.84 & 0.198 \\
\hline Klebsiella spp. & 30 & 11.90 & 20 & 14.49 & 0.465 \\
\hline $\begin{array}{c}\text { Staphylococcus.au } \\
\text { reus }\end{array}$ & 15 & 5.95 & 5 & 3.62 & 0.319 \\
\hline CONS & 14 & 5.55 & 11 & 7.97 & 0.473 \\
\hline Citrobacter spp. & 12 & 4.76 & 8 & 5.79 & 0.658 \\
\hline Acinetobacter spp. & 11 & 4.36 & 1 & 0.72 & 0.047 \\
\hline $\begin{array}{c}\text { Pseudomonas } \\
\text { aeruginosa }\end{array}$ & 7 & 2.77 & 6 & 4.34 & 0.409 \\
\hline Proteus spp. & 5 & 1.98 & 2 & 1.44 & 0.704 \\
\hline Edwardsiella spp. & 1 & 0.39 & 0 & 0 & $\mathrm{NA}$ \\
\hline Total & 252 & & 138 & & \\
\hline
\end{tabular}

Legend: P $>0.005$ (not significant) and $\mathrm{P}<0.005$ (highly significant), NA= Not Applied, UTI= Urinary Tract Infection, OPD= Outpatient Department, IPD=In Patient Department

Table.2 Age and Sex Distribution of Culture Positive Patients

\begin{tabular}{|c|c|c|c|c|c|c|c|c|c|c|c|}
\hline \multirow{2}{*}{$\begin{array}{c}\text { Age in } \\
\text { year }\end{array}$} & \multicolumn{5}{|c|}{ OPD } & \multicolumn{6}{|c|}{ IPD } \\
\hline & $\begin{array}{l}\text { Male } \\
\text { in no. }\end{array}$ & $(\%)$ & $\begin{array}{c}\text { Female } \\
\text { in no. }\end{array}$ & $(\%)$ & Mean \pm SD & $\begin{array}{l}\text { Male } \\
\text { in no. }\end{array}$ & $(\%)$ & $\begin{array}{c}\text { Female } \\
\text { in no. }\end{array}$ & $(\%)$ & Mean \pm SD & P Value \\
\hline $0-10$ & 8 & 6.66 & 0 & 0 & $5.625 \pm 3.50$ & 1 & 10 & 3 & 2.34 & $5.50 \pm 1.73$ & 0.018 \\
\hline $11-20$ & 3 & 2.5 & 15 & 11.36 & $17.88 \pm 2.72$ & 0 & 0 & 15 & 11.71 & $18.73 \pm 2.76$ & 0.233 \\
\hline $21-30$ & 10 & 8.33 & 49 & 37.12 & $24.57 \pm 2.95$ & 5 & 50 & 85 & 66.40 & $24.40 \pm 2.14$ & 0.024 \\
\hline $31-40$ & 9 & 7.5 & 32 & 24.24 & $36.09 \pm 3.33$ & 0 & 0 & 7 & 5.46 & $34.85 \pm 3.18$ & 0.047 \\
\hline $41-50$ & 8 & 6.66 & 24 & 18.18 & $46.59 \pm 3.2$ & 1 & 10 & 8 & 6.25 & $58.20 \pm 3.32$ & 0.654 \\
\hline $51-60$ & 21 & 17.5 & 7 & 5.30 & $58.57 \pm 2.18$ & 2 & 20 & 8 & 6.25 & $58.20 \pm 3.01$ & 0.006 \\
\hline $61-70$ & 29 & 24.16 & 3 & 2.27 & $67.17 \pm 3.05$ & 0 & 0 & 2 & 1.56 & $65.50 \pm 6.36$ & 0.018 \\
\hline $71-80$ & 22 & 18.33 & 1 & 0.75 & $75.34 \pm 2.75$ & 1 & 10 & 0 & 0 & NA & NA \\
\hline$>81$ & 32 & 26.66 & 2 & 1.51 & $86.63 \pm 5.44$ & 0 & 0 & 0 & 0 & NA & NA \\
\hline Total & 120 & & 132 & & & 10 & & 128 & & & \\
\hline
\end{tabular}

Legend: $\mathrm{SD}=$ Standard Deviation, OPD= Outpatient Department, IPD=In Patient Department, NA= Not Applied 
Table.3 In-Vitro Antibiotic Sensitivity in Isolated Gram Negative Uropathogens from OPD

\begin{tabular}{|c|c|c|c|c|c|c|c|c|c|c|c|c|}
\hline Drugs & & E.coli $(\%$ & & Ente & bacter sp & $(\%)$ & Klel & iella spl & $(\%)$ & Citr & acter spp & $\%)$ \\
\hline & $\mathbf{S}$ & IS & $\mathbf{R}$ & $\mathbf{S}$ & IS & $\mathbf{R}$ & $\mathbf{S}$ & IS & $\mathbf{R}$ & $\mathbf{S}$ & IS & $\mathbf{R}$ \\
\hline Gentamicin & $102(86.44)$ & 0 & $16(13.55)$ & $27(79.41)$ & 0 & $7(20.58)$ & $25(83.33)$ & 0 & $5(16.66)$ & 11(91.66) & 0 & $1(8.33)$ \\
\hline Amikacin & $111(93.27)$ & 0 & $8(6.72)$ & $27(87.09)$ & 0 & $4(12.90)$ & $26(89.65)$ & 0 & $3(10.34)$ & $9(81.81)$ & $2(18.18)$ & 0 \\
\hline Ciprofloxacin & $53(46.90)$ & $11(9.73)$ & $49(43.36)$ & $18(64.28)$ & $3(10.71)$ & $7(25)$ & $19(63.33)$ & $2(6.66)$ & $9(30)$ & $8(66.66)$ & 0 & $4(33.33)$ \\
\hline Imipenem & $114(97.43)$ & 0 & $3(2.56)$ & $28(96.55)$ & 0 & $1(3.44)$ & $30(100)$ & 0 & 0 & $8(72.72)$ & 0 & $3(27.27)$ \\
\hline $\begin{array}{c}\text { Ampicillin/sulba } \\
\text { ctam }\end{array}$ & $44(38.93)$ & $4(3.53)$ & $65(57.52)$ & $15(48.38)$ & $1(3.22)$ & $15(48.38)$ & $12(41.37)$ & $1(3.44)$ & $16(55.17)$ & $9(75)$ & 0 & $3(25)$ \\
\hline Ceftriaxone & $47(43.51)$ & 0 & $61(56.48)$ & $12(40)$ & $2(6.66)$ & $16(53.33)$ & $16(53.33)$ & 0 & $14(46.66)$ & $8(66.66)$ & 0 & $4(33.33)$ \\
\hline Cefazolin & $45(41.28)$ & 0 & $64(58.71)$ & $9(33.33)$ & 0 & $18(66.66)$ & $14(50)$ & 0 & $14(58)$ & $6(50)$ & 0 & $6(50)$ \\
\hline Nitrofurantoin & $99(94.28)$ & $2(1.90)$ & $4(3.80)$ & $26(76.47)$ & $3(8.82)$ & $5(14.70)$ & $18(69.23)$ & $1(3.84)$ & $7(26.92)$ & $8(66.66)$ & 0 & $2(16.66)$ \\
\hline
\end{tabular}
Legend: R-Resistant, IS-Intermediate Resistant, S-Sensitive

Table.4 In-Vitro Antibiotic Sensitivity in Isolated Gram Negative Uropathogens from IPD

\begin{tabular}{|c|c|c|c|c|c|c|c|c|c|c|c|c|}
\hline \multirow[t]{2}{*}{ Drugs } & \multicolumn{3}{|c|}{ E.coli (\%) } & \multicolumn{3}{|c|}{ Enterobacter spp. (\%) } & \multicolumn{3}{|c|}{ Klebsiella spp. (\%) } & \multicolumn{3}{|c|}{ Citrobacter spp. (\%) } \\
\hline & $\mathrm{S}$ & IS & $\mathrm{R}$ & $\mathrm{S}$ & IS & $\mathrm{R}$ & $\mathrm{S}$ & IS & $\mathrm{R}$ & $\mathrm{S}$ & IS & $\mathrm{R}$ \\
\hline Gentamicin & $35(59.32)$ & 0 & $24(40.67)$ & 16964) & 0 & $9(36)$ & $14(70)$ & 0 & $6(30)$ & $2(25)$ & 0 & $6(75)$ \\
\hline Amikacin & $32(54.23)$ & $3(5.08)$ & $24(40.67)$ & $14(66.66)$ & 0 & $7(33.33)$ & $15(75)$ & 0 & $5(25)$ & $3(37.5)$ & 0 & $5(62.5$ \\
\hline Ciprofloxacin & $24(43.63)$ & $4(7.27)$ & $27(49.09)$ & $11(52.38)$ & 0 & $10(47.61)$ & $12(60)$ & $1(5)$ & $7(35)$ & $4(57.14)$ & 0 & $3(42.85)$ \\
\hline Imipenem & 49(85.96) & $4(7.01)$ & $4(7.01)$ & $16(76.19)$ & 0 & $5(23.80)$ & $19(95)$ & $1(5)$ & 0 & $5(62.5)$ & 0 & $3(37.5)$ \\
\hline $\begin{array}{c}\text { Ampicillin/sulba } \\
\text { ctam }\end{array}$ & $8(13.55)$ & $1(1.69)$ & $50(84.74)$ & $8(38.09)$ & 0 & $13(61.90)$ & $9(45)$ & $2(40)$ & $9(45)$ & $2(25)$ & 0 & $6(75)$ \\
\hline Ceftriaxone & $11(20.75)$ & 0 & $42(79.24)$ & $7(35)$ & 0 & $13(65)$ & $6(37.5)$ & 0 & $10(62.5)$ & $1(14.28)$ & 0 & $6(85.71)$ \\
\hline Cefazolin & $10(17.24)$ & 0 & $48(82.75)$ & $5(23.80)$ & 0 & $16(76.19)$ & $5(25)$ & 0 & $15(75)$ & $2(25)$ & 0 & $6(75)$ \\
\hline Nitrofurantoin & $45(84.90)$ & $1(1.88)$ & $7(13.20)$ & $19(73.07)$ & 0 & $7(26.92)$ & $14(70)$ & $2(40)$ & $4(20)$ & $4(57.14)$ & 0 & $3(42.85)$ \\
\hline
\end{tabular}

Legend: R-Resistant, IS-Intermediate Resistant, S-Sensitive 
Table.5 In-Vitro Antibiotic Sensitivity in Isolated Gram Positive Uropathogens from OPD

\begin{tabular}{|l|c|c|c|c|c|c|}
\hline Drugs & \multicolumn{3}{|c|}{ Staphylococcus aureus } & \multicolumn{3}{c|}{ CONS } \\
\hline & S & IS & R & S & IS & R \\
\hline Azithromycin & $9(60)$ & 0 & $6(40)$ & $6(46.15)$ & 0 & $7(53.84)$ \\
\hline Vancomycin & $14(93.33)$ & 0 & $1(6.66)$ & $12(92.30)$ & 0 & $1(7.69)$ \\
\hline Linezolid & $13(86.66)$ & $2(13.33)$ & 0 & $11(91.66)$ & 0 & $1(8.33)$ \\
\hline Gentamicin & $13(86.66)$ & 0 & $2(13.33)$ & $13(92.85)$ & 0 & $1(7.14)$ \\
\hline Ofloxacin & $9(60)$ & 0 & $5(33.33)$ & $9(81.81)$ & 0 & $2(18.18)$ \\
\hline Cefoxitin & $10(66.66)$ & 0 & $4(26.66)$ & $7(58.33)$ & 0 & $5(41.66)$ \\
\hline Nitrofurantoin & $8(53.33)$ & 0 & $3(20)$ & $4(66.66)$ & 0 & $2(33.33)$ \\
\hline
\end{tabular}

Legend: R-Resistant, IS-Intermediate Resistant, S-Sensitive

Table.6 In-Vitro Antibiotic Sensitivity in Isolated Gram Positive Uropathogens from IPD

\begin{tabular}{|l|c|c|c|c|c|c|}
\hline Drugs & \multicolumn{2}{|c|}{ Staphylococcus aureus (\%) } & \multicolumn{3}{c|}{ CONS (\%) } \\
\hline & S & IS & R & S & IS & R \\
\hline Azithromycin & $4(80)$ & 0 & $1(20)$ & $2(18.18)$ & 0 & $9(81.81)$ \\
\hline Vancomycin & $3(60)$ & 0 & $2(40)$ & $9(81.81)$ & 0 & $2(18.18)$ \\
\hline Linezolid & $5(100)$ & 0 & 0 & $10(90.90)$ & 0 & $1(9.09 \%)$ \\
\hline Gentamicin & $5(100)$ & 0 & 0 & $4(36.36)$ & 0 & $7(63.63)$ \\
\hline Ofloxacin & $3(60)$ & 0 & $2(40)$ & $4(50)$ & 0 & $4(50)$ \\
\hline Cefoxitin & $1(20)$ & 0 & $4(80)$ & $1(11.11)$ & 0 & $8(88.88)$ \\
\hline Nitrofurantoin & $3(100)$ & 0 & $0(0)$ & $6(75)$ & 0 & $2(25)$ \\
\hline
\end{tabular}

Legend: R-Resistant, IS-Intermediate Resistant, S-Sensitive

The findings are consistent with the previous study conducted by Amit A. Rangari et al., 2015 who also showed that $E$. coli showed high sensitivity to imipenem $98.88 \%$ (178), nitrofurantoin $97.22 \%$ (175) and amikacin $92.77 \%$ (167) but in contrast to our study, Saghir ahmad et al 2014 stated resistance rates for nitrofurantoin $(52.5 \%)$, gentamicin $(70 \%)$, amikacin $(55 \%)$, imipenem $(32.5 \%)$ among uropathogens.

In present study, a high level of bacterial resistance was seen to Ampicillin/sulbactam and ceftriaxone. The resistance was more in IPD patients when compared with OPD patients. This may be due to more use of these higher antibiotics in hospitals. This result is supported by study by Keith S. Kaye et al 2000.Gram positive cocci were sensitive to Vancomycin and linezolid, similar findings were seen in study by Zahra
Tayebi et al., 2014 who also concluded that Vancomycin seem to be the most effective drugs for treatment of gram positive cocci causing UTI.

The most effective antimicrobial agents in our study in IPD patients were imipenem, nitrofurantoin and gentamicin for Gram negative bacilli and in OPD patients the most effective antibiotics were imipenem, nitrofurantoin and amikacin. However, isolated Gram positive cocci in both IPD and OPD patients were fully sensitive to vancomycin and linezolid.

In conclusion, Urinary tract infections pose a great threat to health and impose an economic and social burden due to the stigma associated with these infections. Gram negative organisms are most commonly isolated organisms in UTI among 
which E.coli is the biggest culprit. Females are more prone to UTIs. Isolates showed lower resistance rates to Imipenem, Amikacin and Nitrofurantoin. Therefore these can be used as empirical treatment in patients with symptoms of UTI. Routine surveillance and monitoring studies should be conducted to help physician to initiate most effective empirical treatment.

\section{References}

Abubakar, E.M. 2009. Antimicrobial susceptibility pattern of pathogenic bacteria causing urinary tract infections at the Specialist Hospital, Yola, Adamawa State, Nigeria. J. Clin. Med. Res., 1(1): 001-008.

Adedeji, B.A.M., Abdulkadir, O.A. 2009. Etiology and antimicrobial resistan pattern of bacterial agents of urinary tract infections in students of tertiary institution in Yola metropolis. Adv. Biomed. Res., 3(3-4): 67-70.

AlkaNerurkar. 2012. Bacterial pathogens in urinary tract infection and antibiotic susceptibility pattern. J. Pharma. Biomed. Sci., 21(12).

Amit, A., Rangari, Sachin Sharma, Nidhi Tyagi, Paramjit Singh, Garima Singh, Rameshwari Thakur. 2015. Antibiotic Susceptibility Pattern of Bacterial Uropathogens Isolated from Patients at a Tertiary Care Hospital in Western Uttar Pradesh of India. Int. J. Curr. Microbiol. App. Sci., 4(10): 646-657.

Bano, K., Khan, J., Rifat, Begum, H., Munirs, Akbar, N., et al. 2012. Patterns of antibiotic sensitivity of bacterial pathogens among urinary tract infections (UTI) patients in a Pakistani population. Afri. J. Microbiol. Res., 6: 414-20.

Banerjee, S. 2009. The study of urinary tract infections and antibiogram of uropathogens in and around Ahmadnagar, Maharashtra. The Internet J. Infect. Dis., 9(1).

Clinical and Laboratory Standards Institute. 2006. Performance standards for antimicrobial disk tests: approved standard. $9^{\text {th }}$ ed. CLSI document M2A9, Vol 26(1), Wayne, PA.

Daza, R., Gutierrez, J., Piedrola, G. 2001. Antibiotic susceptibility of bacteria strains isolated from Patients with community-acquired urinary tract infections. Int. J. Antimicrob. Agents, 18: 211-15.

Hari Kattel, P. 2008. Bacteriology of Urinary Tract Infection among patients attending Tribuvan University Teaching Hospital Kathmandu, Nepal. J. Nepal Assoc. Med. Lab. Sci., 9(1): 25-29.

Keith, S., Kaye, Anthony, D., Harris, Howard Gold, Yehuda Carmeli. 2000. Risk Factors for Recovery of Ampicillin-Sulbactam-Resistant Escherichia coli in Hospitalized patients. Antimicrob. Agents Chemother., 44(4): 1004-1009.

Kumar, M.S., Lakshmi, V., Rajagopalan, R. Related Articles. 2006. Occurrence of extended spectrum betalactamases among Enterobacteriaceae spp. isolated at a tertiary care institute. Ind. J. Med. Microbiol., 24(3): 208-11.

Mohammed Akram, Mohammed Shahid, Asad U Khan. 2007. Etiology and antibiotic resistance patterns of community-acquired urinary tract infections in $\mathrm{J} \mathrm{N}$ M C Hospital Aligarh, India. Ann. Clin. Microbiol. Antimicrobiol., 6(1): 4.

Mohamed Shaaban, T., Hassan Ghozlan, A., Marwa Maghra, M.E. 2012. Susceptibility ofBacteria Infecting Urinary Tract to Some Antibiotics 
and Essential Oils. J. Appl. Pharma. Sci., 02(04): 90-98.

Omoregie, R., Erebor, J.O., Ahonkhai, I., Isibor, J.O., Ogefere, H.O. 2008. Observed changes in the prevalence of uropathogens in Benin City, Nigeria. New Zealand J. Med. Lab. Sci., 62: 29-33.

Performance standards for antimicrobial susceptibility testing. 25st Informational Supplement. (M100S25). Clinical and Laboratory Standards Institute (CLSI, 2015). Wayne, Pa, USA: Clinical and Laboratory Standards Institute.

Saghir Ahmad Jafri, Muhammad Qasim, Muhammad Masoud, Mahmood-ur-Rahman, Mateen Izhar, Saqib Kazmi. 2014. Antibiotic resistance of $E$. coli isolates from urine samples of Urinary Tract Infection (UTI) patients in Pakistan. Bioinformation, 10(7): 419-422.

Shanthi, J. 2012. Incidence, distribution and antibiogram of uropathogens isolated from patientswith urinary tract infections. Adv. Appl. Sci. Res., 3(6): 3410-3414.

Winn, Jr. W.C., Allen, S.D., Janda, W.M., Koneman, E.W., Procop, G.W.,
Schreckenberger, P.C., et al. (Eds). 2006. Antimicrobial susceptibility testing. In:Koneman' s color atlas and textbook of diagnostic microbiology, 6th edn. Lippincott Williams and Wilkins, Philadelphia. pp. 946-1014.

Yüksel, S., Oztürk, B., Kavaz, A., Ozçakar, Z.B., Acar, B., Güriz, H., Aysev, D., Ekim, M., Yalçinkaya, F. 2006. Antibiotic resistance of urinary tract pathogens and evaluation of empirical treatment in Turkish children with urinary tract infections. Int. J. Antimicrob. Agents, 28(5): 413-6.

Zahra Tayebi, Sima Sadat Seyedjavadi, Mehdi Goudarzi, 2014. Frequency and antibiotic resistance pattern in gram positive uropathogens isolated from hospitalized patients with urinary tract infection in Tehran, Iran. J. Gene, Microbes and Immunity, 1-9.

Zelikovic, Adelman, R.D., Nancarrow, P.A. 1992. Urinary tract infections in children an update. Western J. Med., 157(5): 554-561.

\section{How to cite this article:}

Surinder Kumar, Diksha Budhani and Pallavi Sayal. 2016. Bacterial Uropathogens and Empirical Treatment in Urinary Tract Infection in a Tertiary Care Institute. Int.J.Curr.Microbiol.App.Sci. 5(4): 47-54. doi: http://dx.doi.org/10.20546/ijcmas.2016.504.008 